\title{
日韓鼻科学ジョイントセッション
}

\section{Olfactory event-related potentials: normative data in Koreans}

\author{
Jin Kook Kim \\ Professor, Konkuk University School of Medicine
}

Olfactory event-related potential (OERP) has been considered as an important alternative method to evaluate olfactory function. OERP correlates directly with neuronal activation, has an extremely high temporal resolution in the range of microseconds, and allows the investigation of the sequential processing of olfactory information. OERP also has been used to investigate the processing of odorous information in olfactory dysfunction. The purpose of the current study is to further define the effects of age, gender, and their interactions on the olfactory evoked potential in Koreans. Participants were 71 people (who were) screened for nasal health and olfactory dysfunction. The odor stimulus was $\beta$-mercaptoethanol $1 \mathrm{M}$, presented at nasal temperature in a humidified airstream delivered by an air-dilution olfactome- ter at a constant flow rate, using a 60 second inter-stimulus interval. OERPs were recorded at $\mathrm{Fz}, \mathrm{Cz}$, and $\mathrm{Pz}$ electrode sites, (BrainAmp MR plus 32, Brain product $\mathrm{GmbH}$, Germany) amplified and averaged over trials. Amplitudes of the N1/P2 and P3 and latencies of the P2 and P3 were analyzed. Amplitudes of the N1/P2 and P3 were decreased across the life span, significantly. Especially an age-related decline of N1/P2 amplitude was prominent in both male and female. Latencies of the P2 and P3 were increased across the life span, significantly. Latency of P3 was increased in male and female, significantly. Normative data will be useful in research on olfactory function and in clinical assessment of olfactory functional status. 